\title{
Evaluation of Pavement Distress for Asphalt Pavement Using Pavement Condition Index: Case Study from Adama to Awash Arba
}

\author{
Ashebir Belete Werkineh", ${ }^{1,}$, Bekele Arega Demissie ${ }^{2}$ \\ ${ }^{1}$ Department of Civil Engineering, College of Engineering, Assosa University, Assosa, Ethiopia \\ ${ }^{2}$ Department of Civil Engineering, Assosa University, Assosa, Ethiopia \\ Email address: \\ itemanchi1888@gmail.com (A. B. Werkineh), aregabekalu@gmail.com (B. A. Demissie) \\ ${ }^{*}$ Corresponding author
}

\section{To cite this article:}

Ashebir Belete Werkineh, Bekele Arega Demissie. Evaluation of Pavement Distress for Asphalt Pavement Using Pavement Condition Index: Case Study from Adama to Awash Arba. American Journal of Science, Engineering and Technology. Vol. 4, No. 4, 2019 , pp. $73-79$. doi: 10.11648/j.ajset.20190404.13

Received: November 11, 2019; Accepted: December 2, 2019; Published: December 13, 2019

\begin{abstract}
Pavement distress is a common problem for an opening road network and this distress is caused due to overloading of vehicles, poor maintenance, rapid traffic growth and improper design and implementation. This research study focused in Adama to Awash-Arba road section. The main objective of this research work was to evaluate the pavement distress using pavement condition index for the road section from Adama to Awash Arba. The result of the research show that the PCI value range from 8 to 97.1 and this shows that all section of the road have all types of pavement condition rating (Good, Satisfactory, Fair, Very Poor, Poor, Serious and Failed) in which $12.12 \%$ good, $9.09 \%$ satisfactory, $18.18 \%$ fair, $21.21 \%$ poor, $18.18 \%$ very poor, $18.18 \%$ serious and $3.03 \%$ was failed. Based on the pavement condition rating, seven soil samples was collected for the failed and serious road section using manual hand auger. Samples were airdried before taken to laboratory test determination of subgrade soil. According to the pavement condition survey the road section from Adama to Awash Arba required maintenance and based on this, possible maintenance option had been recommended for pavement distress with respect to level of severity on the pavement condition of the study area in order to sustain the design life of the Pavement.
\end{abstract}

Keywords: Pavement Condition Index (PCI), Pavement Condition Rating (PCR), Pavement Defects, Distress Types, Distress Severity Level

\section{Introduction}

Pavements form a greater part of our society's infrastructure system whose proper functioning is essential for development. Similar to other types of infrastructure assets, pavements deteriorate over time. Therefore, there is the need to find ways to preserve these capital intensive assets to ensure they perform as expected [3].

The increasing traffic intensity, high tire pressure, increasing axle loads etc... are causing early signs of distress to bituminous pavements throughout the world. The deterioration of the paved roads in tropical and subtropical countries differs from those in the more temperate regions of the world. This can be due to the harsh climatic conditions and sometimes due to the lack of good pavement materials and construction practices [1].

Highways in 2002, Ethiopia has a total of $33297 \mathrm{~km}$ of road, both paved and gravel road. This is the first part of Road Sector Development Program which ends last 2002 G. C. As of 2006 G. C, Ethiopia only had one expressway that is the Addis Ababa Ring Road. This is a four-lane limitedaccess divided highway, which forms a beltway around the capital. Ethiopian Roads Authority and China Communications Construction Consultancy just finished building the new six-lane expressway between Addis Ababa and Adama. The expressway is $80 \mathrm{~km}$ long, will shorten the distance by $20 \mathrm{~km}$ [6]. 


\section{Conventional Flexible Pavements}

Conventional flexible pavements are multi-layered structures with better materials on top where the intensity of stress is high and inferior materials at the bottom where the intensity is low. This design principle makes possible to use local materials and usually results in a most economical design. This is particularly true in regions where high-quality materials are expensive but local materials of inferior quality are readily available [13].

\section{Full-Depth Asphalt Pavements}

Full-depth asphalt pavements are constructed by placing one or more layers of hot-mix asphalt directly on the subgrade or improved subgrade. This concept was conceived by the Asphalt Institute and is generally considered the most cost-effective and dependable type of asphalt pavement for heavy traffic and quite popular in areas where local materials are not available [13].

\section{Types of Pavement Deterioration}

The four major categories of common asphalt pavement surface distresses are [4]:

1. Cracking.

2. Surface deformation.

3. Disintegration.

\subsection{Cracking}

The most common types of cracking are:

1. Fatigue cracking.

2. Longitudinal cracking.

3. Transverse cracking.

4. Block cracking.

5. Slippage cracking.

6. Reflective cracking.

\subsection{Surface Deformation}

Pavement deformation is the result of weakness in one or more layers of the pavement that has experienced movement after construction. The deformation may be accompanied by cracking. Surface distortions can be a traffic hazard.

The basic types of surface deformation are:

1. Rutting.

2. Corrugation.

\subsection{Disintegration}

Alligator or fatigue cracking is a series of interconnecting cracks caused by fatigue failure of the asphalt concrete surface under repeated traffic loading. Cracking begins at the bottom of the asphalt surface, or stabilized base, where tensile stress and strain are highest under a wheel load. The pieces are generally less than $0.5 \mathrm{~m}(1.5 \mathrm{ft})$ on the longest side. Alligator cracking occurs only in areas subjected to repeated traffic loading, such as wheel paths. Pattern-type cracking that occurs over an entire area not subjected to loading is called "block cracking," which is not a loadassociated distress $[3,15]$.

\section{Alligator Cracking (Fatigue)}

\subsection{Description}

Alligator cracking is measured in square meters (square feet) of surface area. The major difficulty in measuring this type of distress is that two or three levels of severity often exist within one distressed area. If these portions can be easily distinguished from each other, they should be measured and recorded separately; however, if the different levels of severity cannot be divided easily, the entire area should be rated at the highest severity present. If alligator cracking and rutting occur in the same area, each is recorded separately as its respective severity level $[3,15]$.

\subsection{How to Measure Alligator Cracking}

Alligator cracking is measured in square meters (square feet) of surface area. The major difficulty in measuring this type of distress is that two or three levels of severity often exist within one distressed area. If these portions can be easily distinguished from each other, they should be measured and recorded separately; however, if the different levels of severity cannot be divided easily, the entire area should be rated at the highest severity present. If alligator cracking and rutting occur in the same area, each is recorded separately as its respective severity level. [3]

\section{Block Cracking}

\subsection{Description}

Block cracks are interconnected cracks that divide the pavement into approximately rectangular pieces. The blocks may range in size from approximately 0.3 by $0.3 \mathrm{~m}$ ( 1 by 1 $\mathrm{ft})$ to 3 by $3 \mathrm{~m}$ (10 by $10 \mathrm{ft}$ ). Block cracking is caused mainly by shrinkage of the asphalt concrete and daily temperature cycling, which results in daily stress/strain cycling. It is not load-associated. Block cracking usually indicates that the asphalt has hardened significantly. This type of distress differs from alligator cracking in that alligator cracks form smaller, many-sided pieces with sharp angles. Also, unlike block, alligator cracks are caused by repeated traffic loadings, and therefore, are found only in traffic areas, that is, wheel paths [3].

\subsection{How to Measure Block Cracking}

Block cracking is measured in $\mathrm{m}^{2}$ given pavement section; however, if areas of different severity levels can be distinguished easily from one another, they should be measured and recorded separately [3]. 


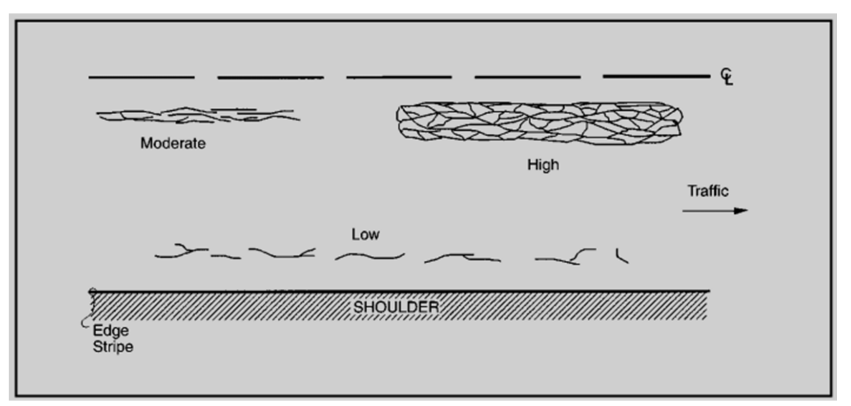

Figure 1. Fatigue Cracking [2].

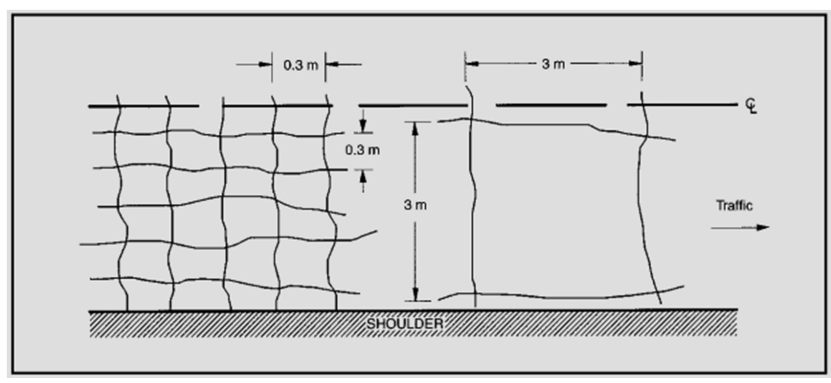

Figure 2. Block Cracking [2].

\section{Rutting}

\subsection{Description}

A rut is a surface depression in the wheel paths. Pavement uplift may occur along the sides of the rut, but, in many instances, ruts are noticeable only after a rainfall when the paths are filled with water [1].

\subsection{How to Measure}

Rutting is measured in square meters (square feet) of surface area, and its severity is determined by the mean depth of the rut. The mean rut depth is calculated by laying a straight edge across the rut, measuring its depth, then using measurements taken along the length of the rut to compute its mean depth in millimetres [3].

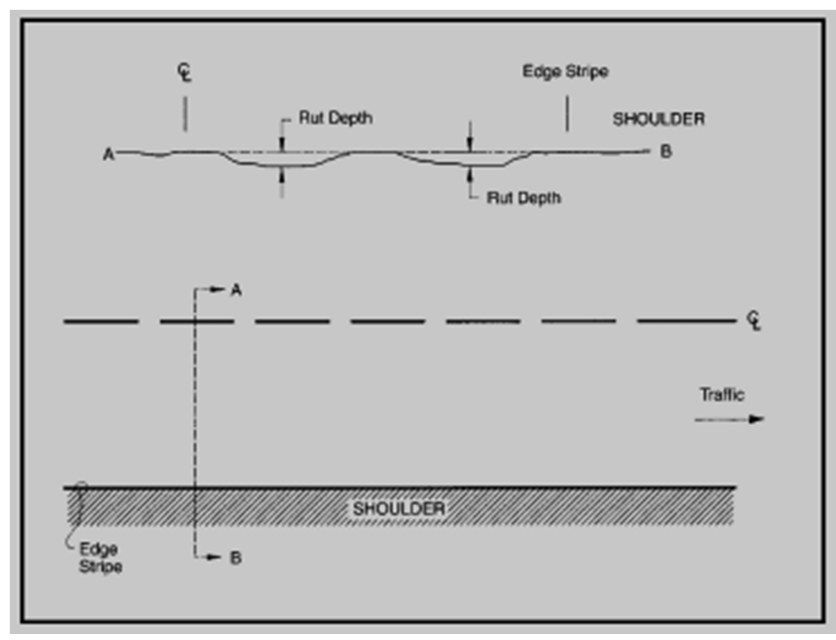

Figure 3. Rutting [2].

\section{Shoving}

\subsection{Description}

Shoving is a permanent, longitudinal displacement of a localized area of the pavement surface caused by traffic loading. When traffic pushes against the pavement, it produces a short, abrupt wave in the pavement surface. This distress normally occurs only in unstable liquid asphalt mix (cutback or emulsion) pavements. Shoves also occur where asphalt pavements abut PCC pavements. The PCC pavements increase in length and push the asphalt pavement, causing the shoving [3, 4].

\subsection{How to Measure}

Shoves are measured in square meters (feet) of surface area. Shoves occurring in patches are considered in rating the patch, not as a separate distress [3].

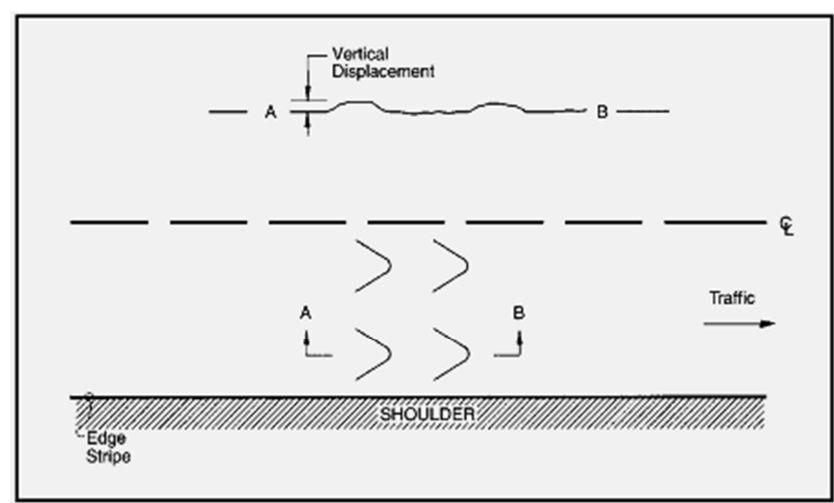

Figure 4. Shoving [7].

\section{Visual Assessment of Pavement Surface}

Surveys are conducted visually by foot, which provides the best vantage point for observing the actual condition of the pavement surface. By standing or walking the pavement surface, the pavement rater has the opportunity to closely observe pavement distresses such as cracks, weathering, ravelling, and rutting, allowing for a better assessment of the amount of distress in a specific survey location [3].

\section{Pavement Condition Index (PCI)}

Pavement Condition Index rates the condition of the surface of a road network. The PCI provides a numerical rating for the condition of road segments within the road network, where 0 is the worst possible condition and 100 is the best [5].

\section{Pavement Condition Rating}

A verbal description of pavement condition as a function of the PCI value that varies from "failed" to "good" [3]. 
Table 1. Pavement condition ratings and pavement condition index [3].

\begin{tabular}{ll}
\hline Pavement condition index & Pavement condition rating \\
\hline $0-10$ & Failed \\
$10-25$ & serious \\
$25-40$ & Very poor \\
$40-55$ & poor \\
$55-70$ & Fair \\
$70-85$ & Satisfactory \\
$85-100$ & Good \\
\hline
\end{tabular}

\section{Asphalt Maintenance Operations}

Today's increasing budget constraints require that state and local agencies perform more work with less money. Historically, the emphasis of local highway departments has been on building new roads, but the new focus is on maintaining and preserving existing pavement surfaces. This shift has resulted in three types of pavement maintenance operations [2].

Types of Maintenance Treatments Technique

\subsection{Crack Repair with Sealing}

A localized treatment method used to prevent water and debris from entering a crack, which might include routing to clean the entire crack and to create a reservoir to hold the sealant [2].

\subsection{Crack Filling}

Differs from crack sealing mainly in the preparation given to the crack prior to treatment and the type of sealant used [2].

\subsection{Full-depth Crack Repair}

A localized treatment method to repair cracks that are too deteriorated to benefit from sealing [2].

\subsection{Seal Coat}

A seal coat is an application of asphalt followed immediately with an aggregate cover. Applications with two layers are referred to as a double chip seal [2].

\subsection{Slurry Seal}

A slurry seal is a mixture of fine aggregate, asphalt emulsion, water, and mineral filler [2].

\subsection{Micro Surfacing}

Micro surfacing is sometimes incorrectly referred to as a polymer-modified slurry seal [2].

\subsection{Thin Hot-mix Overlays}

Thin hot-mix asphalt (HMA) overlays are blends of aggregate and asphalt cement [2].

\section{Pavement Management Systems}

A Pavement Management System (PMS) is the name given to a tool or method that assists in optimizing strategies for providing and maintaining pavements in a serviceable condition over a given period of time. One of the primary benefits of a pavement management system is that it helps user's select cost-effective alternatives for pavement maintenance and rehabilitation [2].

\section{Methodology}

\subsection{Study Variable}

The study variables both dependent and independent are assessed in this research. Which display the pavement distress from Adama to Awash Arba.

\subsection{Independent Variables}

1. Pavement Condition Index.

2. Grain Size/Gradation.

3. Atterberg Limits.

4. Compaction test.

5. California Bearing Ratio (CBR).

\subsection{Data Collection Process}

In order to attain the purpose of this research work ethical considerations was concentrating on in the context of quantitative and qualitative research. Before starting any data collection formal letter was obtained from JIT and an official permission was obtained from concerned bodies. Data collection process included field visual inspection, Field measurements and laboratory tests were conducted.

The type of data was collected from the field with in an interval length $1000 \mathrm{~m}$ by width of $7.2 \mathrm{~m}$ for the study $141 \mathrm{Km}$ and the data (type and severity levels of distress) was recorded on the data sheet for PCI determination shown in figures 3 and 4 . The data was collected using visual survey method by the researcher and daily labour. And for the section which show failed and serious pavement condition rating a laboratory test were conducted for subgrade soils.

\subsection{Field Work}

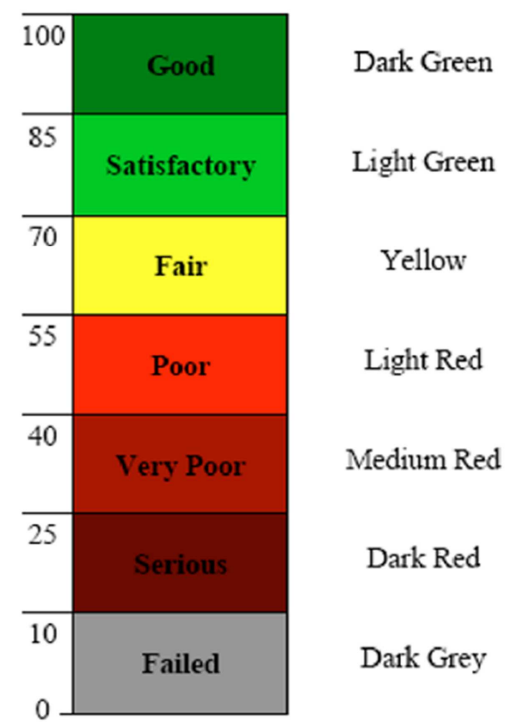

Figure 5. Pavement Condition Index (PCI), Rating scale and suggested colour [3]. 
A manual survey is performed following ASTM D 6433. The pavement was divided into sections. Each section was divided into sample units. The type and severity of sample distress was assessed by visual inspection of the pavement sample units and the quantity of each distress was measured.

Typically, this procedure requires a team of at least two engineers.

Before starting of the detail pavement evaluation, the entire road length was visually assessed and it is attempted to identify the types of failures occurred on the road surface. After finishing of the pavement condition survey, seven soil samples were collected for failed and serious road condition rating. The following representative photographs can show the type of failures and measurement along Adama to Awash Arba Road section the road.

\subsection{Laboratory Tests}

1. Atterberg limit.

2. Grain Size Distributions (Gradation).

3. Soil compaction.

4. Subgrade soil classification.

5. California Bearing Ratio (CBR).

\section{Result and Discussion}

\subsection{General}

Asphalt Concrete (AC) Surfaced Pavement —individually inspect each sample unit chosen. Sketch the sample unit. Record the branch and section number and the number and type of the sample unit. Record the sample unit size measured with the hand odometer. Conduct the distress inspection by walking over the sidewalk/shoulder of the sample unit being surveyed, measuring the quantity of each severity level of every distress type present, and recording the data. Each distress must correspond in type and severity to that described in Appendix A. The method of measurement is included with each distress description. Repeat this procedure for each sample unit to be inspected.

\subsection{Field Condition Survey Result and Discussion}

\subsubsection{Types of Pavement Distress}

For entire section inspections, the inspector walks over each sample unit, measures each distress type and severity, and records the data on the Asphalt Pavement Inspection Sheet. The letter L (low), M (medium), or $\mathrm{H}$ (high) is included along with the distress number code to indicate the severity level of the distress. Distresses and severity level definitions are listed in Chapter two.

Table 2. Types of pavement exist on the study area.

\begin{tabular}{llll}
\hline Types of pavement & \multicolumn{3}{l}{ Level of severity } \\
\cline { 2 - 4 } distress & Low & Medium & High \\
\hline Alligator cracking & $\sqrt{ }$ & $\sqrt{ }$ & $\sqrt{ }$ \\
Bleeding & $\sqrt{ }$ & $\sqrt{ }$ & \\
Block cracking & & $\sqrt{ }$ & \\
Corrugation & & $\sqrt{ }$ & $\sqrt{ }$ \\
\hline
\end{tabular}

\begin{tabular}{llll}
\hline Types of pavement & \multicolumn{2}{l}{ Level of severity } \\
\cline { 2 - 4 } distress & Low & Medium & High \\
\hline Depression & $\sqrt{ }$ & $\sqrt{ }$ & $\sqrt{ }$ \\
Edge cracking & $\sqrt{ }$ & $\sqrt{ }$ & $\sqrt{ }$ \\
Long \& travs cracking & $\sqrt{ }$ & $\sqrt{ }$ & $\sqrt{ }$ \\
Patching & & & \\
Polished aggregate & & $\sqrt{ }$ & $\sqrt{ }$ \\
Potholes & $\sqrt{ }$ & $\sqrt{ }$ & $\sqrt{ }$ \\
Railroad crossing & & $\sqrt{ }$ & \\
Rutting & $\sqrt{ }$ & $\sqrt{ }$ & \\
swell & $\sqrt{ }$ &
\end{tabular}

\subsubsection{Pavement Condition Rating}

Pavement Condition Rating (PCR) is a verbal description of pavement condition as a function of the Pavement Condition Index (PCI) value that varies from "failed" to "good". Based on the field condition survey, all types of pavement condition rating were exist in the study area along the road section from Adama to Awash Arba and the condition of each results is show in the following tables.

Table 3. Percentage of pavement condition rating.

\begin{tabular}{lll}
\hline PCR & TOTAL NUMBER of PCR & Percentage of PCR (\%) \\
\hline Good & 4 & 12.12 \\
Satisfactory & 3 & 9.09 \\
Fair & 6 & 18.18 \\
Poor & 7 & 21.21 \\
Very poor & 6 & 18.18 \\
Serious & 6 & 18.18 \\
Failed & 1 & 3.03 \\
\hline
\end{tabular}

There are more than 10 pavement distresses in the study area. The following table shows the types of pavement exists along the study area.

The starting point of this research was at Adama town Derartu Tulu roundabout and ends at Awash Arba entrance.

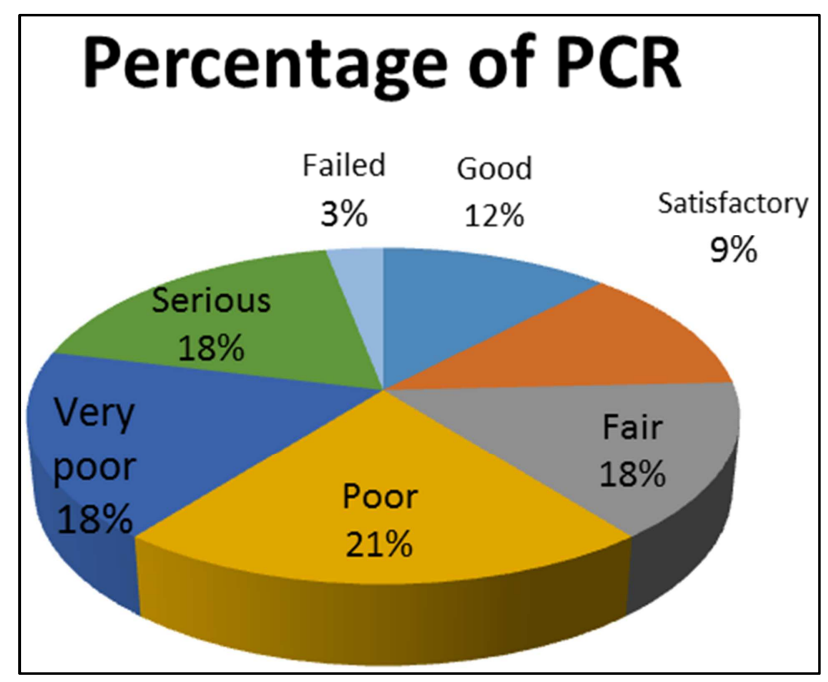

Figure 6. Percentage Pavement condition rating.

\subsection{Laboratory Test Result and Discussion for Failed and Serious PCR}

\subsubsection{Grain Size Analysis}

The soils were classified by ASSHTO under the A-6 and 
A-7-6 category which showed that usual types of significant constituent materials was clayey with general rating of a soil fair to poor as a sub-grade material.

\subsubsection{Atterbergs Limit Test}

The sub-grade soil (i.e. LL $<80 \%$ and PI $<55 \%$ ) it satisfies the specification; grouped into A-6 and A-7-6 in AASHTO soil classification system and USCS as Sand lean clay (CL) for all stations except for station $83+000-84+000$ which is Gravelly lean clay with sand.

According to ERA manual (2002), soils with PI values less than $25 \%$ and $L L<50$ are suitable subgrade materials so that all station show suitable subgrade materials for failed and serous pavement condition rating (PCR).

\subsubsection{Compaction Test}

The Subgrade soil laboratory test maximum dry (MDD) densities are between $1.338 \mathrm{~g} / \mathrm{cm}-1.533 \mathrm{~g} / \mathrm{m} 3$ while optimum moisture content (OMC) ranges from $12 \%-24.1 \%$.

\subsubsection{Subgrade Soil Classification}

The soils were classified by ASSHTO under the A-6 and A-7-6 category which showed that usual types of significant constituent materials was clayey with general rating of a soil fair to poor as a sub-grade material.

\subsubsection{California Bearing Ratio}

The results of the CBR test show that samples from all sites have CBR values greater than $5 \%$. These samples are therefore good subgrade materials and suitable borrow fill materials.

The percent swell test results are found below $1 \%$ which is an indication of less expansiveness of the soil which is very good as a subgrade material. Therefore these values indicate that the cause of pavement failure for failed and serious pavement condition rating was not the subgrade soil.

\subsection{Estimation of the Maintenance Option for Pavement Distress}

The selected road section condition was full of cracking, surface deformation, and disintegration and surface defects. For Cracking use one of this technique Clean and Seal, Fulldepth crack Repair, seal coat or thin hot-mix Overlay and for surface treatment technique such as seal coat, double chip seal, slurry seal or thin hot-mix overlay by observing level of severity. And the sections with various sizes of potholes should be patched with good quality of asphalt.

Table 4. Maintenance suggestion.

\begin{tabular}{lll}
\hline Pavement distress & Severity level & Maintenance option \\
\hline \multirow{2}{*}{ Corrugation } & medium & Thin hot-mix overlay \\
Depression & high & Thin hot-mix overlay \\
& low & Patching \\
low & Slurry seal, Patching \\
Rutting & medium & Slurry seal, Patching, or Thin \\
& hot-mix overlay \\
& low & Patching, or Thin hot-mix overlay \\
swell & medium & Thin hot-mix overlay \\
& & Thin hot-mix overlay \\
\hline
\end{tabular}

\section{Conclusion}

Based on field work pavement condition survey and laboratory results the conclusion is as follows:

The pavement condition survey along the selected road shows that there were different failure type such as alligator cracking, bleeding, block cracking, corrugation, depression, edge cracking, longitudinal and transverse cracking, patching, polished aggregate, potholes, railroad crossing, rutting and swell.

The result of the research show that the PCI value range from 8 to 97.1 which shows that all section of the road had all types of pavement condition Rating (Good, Satisfactory, Fair, Very Poor, Poor, Serious and Failed). From the field work pavement condition survey was collected as $12.12 \%$ good, $9.09 \%$ satisfactory, $18.18 \%$ fair, $21.21 \%$ poor, $18.18 \%$ very poor, $18.18 \%$ serious and $3.03 \%$ failed.

A laboratory soil investigation for failed and serious pavement condition rating show that the liquid limit varies from $33.02 \%-44.48 \%$ and Plasticity index from $11.3 \%$ $25.56 \%$, according to ERA manual, soils with LL $<50 \%$ and PI $>25 \%$ are suitable subgrade materials so all station are good. The soils were classified by ASSHTO under the A-6 and A-7-6 category which showed that the soils were fair to poor as a sub-grade material. The soaked CBR values of subgrade soil materials are between $7.9 \%$ $10.4 \%$. According to ERA manual CBR values greater than $5 \%$ are good subgrade materials. Therefore, from the laboratory test results the subgrade soil was not the cause of pavement failure for failed and serious pavement condition rating.

\section{Acknowledgements}

First of all, I would like to thanks and praise my God for his guidance and success in my life.

Acknowledgements are due to my parents for their love and encouragement during my study.

Last but not least I would like to extend my deepest thanks to my friend Mr. Mukesh Kumar for his guidance and help to write this manuscript throughout for motivating me.

\section{References}

[1] AASHTO, (1993), "Guide for design of pavement structures", American Association of State Highway and Transportation Officials.

[2] Ann M., Johnson, P. E. (2000), "Best Practices Handbook on Asphalt Pavement Maintenance", Centre for Transportation Studies, University of Minnesota.

[3] ASTM D 6433-07, (2007) Standard Practice for Roads and Parking Lots Pavement Condition Index Surveys, American Society for Testing and Materials.

[4] Battiato S., Rizzo L., Stanco F., Cafiso S., Di Graziano A. (2006) - Pavement Surface Distress by Using Non-linear Image Analysis Techniques - Symposium SIMAI Ragusa. 
[5] Di Graziano A., Ortiz Garcia J. (2003) - Acceptability of multicriteria analysis as a tool for developing pavement maintenance standards in local authorities - XXII PIARC Proc., Durban.

[6] Elmer, C.A. (2015). Transport economics lecture note. Jimma institute of Technology. pp7-8

[7] Lee H. D., Kim J. J. (2005) - Development of a manual crack quantification and automated crack measurement system Project TR 457 University of Iowa.

[8] Bowles, J. E. (1984) Engineering Properties of Soils and Their Measurement, McGraw-Hill, Singapore, second edition.

[9] David, T., Jason, M. Q. (2004). A Study of Manual vs. Automated Pavement Condition Surveys. Auburn Alabama.

[10] Deepika, C. V. (2012). Evaluation of properties of soil sub grade using dynamic cone penetration index-a case study. International journal of engineering research and development. 7.
[11] ERA. (2002) Ethiopian Roads Authority Standard Manuals. Pavement Design Manual: Flexible Pavements and Gravel Roads, Volume I.

[12] Federal Highway Administration (FHA), (2009) Pavement Distress Identification Manual, Department of Transportation, United States.

[13] Gupta, K. A., Adlinge, S. S. (1998). Pavement Deterioration and its Causes. Journal of Mechanical \& Civil Engineering. Shivaji University, India.

[14] Mohammed, H., Dahunsi, B. (2012) Effects of Natural Moisture Content On Selected Engineering Properties Of Soils, Transnational Journal of Science and Technology.

[15] U.S. Army Corps of Engineers (2001). Paver Asphalt Surfaced Airfields Pavement Condition Index (PCI), UNIFIED FACILITIES CRITERIA (UFC). 